〔Med. Entomol. Zool. Vol. 61 No. 3 p. 309-319 2010〕

\title{
The genus Opalimosina Roháček (Diptera, Sphaeroceridae) from Japan
}

\author{
Toshihiko HAYASHI \\ Department of Medical Entomology, National Institute of Infectious Diseases, \\ Toyama 1-23-1, Shinjuku-ku, Tokyo 162-8640, Japan
}

(Received: 28 April 2010; Accepted: 31 May 2010)

\begin{abstract}
Six species of the genus Opalimosina Roháček are recorded from Japan. Three species are new to science; Opalimosina (O.) dolichodasys sp. nov. (Hokkaido), O. (O.) monticola sp. nov. (Hokkaido, Honshu) and O. (O.) spathulata sp. nov. (Hokkaido, Honshu, Okinawa-honto Is., Ishigaki Is. and Iriomote Is.). Opalimosina (Hackmanina) czernyi (Duda) and O. (O.) australis Hayashi are newly recorded from Japan.
\end{abstract}

Key words: Opalimosina, Sphaeroceridae, Diptera, Japan, new species

The genus Opalimosina was erected by Roháček (1983), consisting of 7 species of 4 subgenera. The distribution of this genus is mainly the Palaearctic Region, but 3 species are added from the Oriental and Australasian Regions thereafter (Hayashi, 1989, 2009; Papp, 1991). The adults are found on animal dung and leaf litter. Opalimosina (O.) mirabilis (Collin) is commonly found on cattle dung, and now a cosmopolitan species owing to human activity.

In Japan, only one species, O. (O.) mirabilis was recorded (Hayashi, 1986a, b, 2005). I studied Japanese material of the genus Opalimosina, and found 6 species, including 3 new species. I describe and illustrate these new species, and illustrate male sternites 5 and external genitalia of all species recorded in Japan in this paper.

The specimens examined in this study including type series are preserved in the Reference Museum, Department of Medical Entomology, National Institute of Infectious Diseases, Tokyo.

\section{Opalimosina Roháček, 1983 (Japanese name: Kagizume-funkobae-zoku)}

Diagnosis. Body length 0.8-2.3 mm, body color brown to dark brown; 3-4 short if, pvt always present; wing without dark markings, costa ending at or slightly beyond $\mathrm{R}_{4+5}$, $\mathrm{R}_{4+5}$ slightly but distinctly bent to costa, discal cell rather narrow and long, alula small, narrow and pointed; hind tibia with a distinct ventral spine in many species (the subgenus Opalimosina); male inner genitalia with large epiphallus; female cercus always without sinuate hairs but sometimes with strong spines.

Remarks. Roháček (1983) erected this genus containing 4 subgenera. Of these, 2 subgenera are found in Japan (subgenera Hackmanina and Opalimosina). In the Japanese species of subgenus Opalimosina, all species have a distinct ventral spine on hind tibia, and therefore, the species are easily distinguishable from the species of other genera by this character. Some species resemble one another very much, and are distinguished only by the postabdominal structures. 


\section{Key to Japanese species of Opalimosina}

1. Hind tibia without a spine .................... (Hackmanina) czernyi (Duda)

- Hind tibia with a distinct spine (Figs. 14, 20, 22 and 29) . ..............

2. Hind tibial spur (Fig. 20) large, almost $1 / 2$ as long as hind tibia; costa (Fig. 4) a little beyond the end of $\mathrm{R}_{4+5}$; male sternite 5 (Fig. 11) devided into 2 parts, posteromedial part with a pair of batch of long setae; female cercus with an apically curved distinct

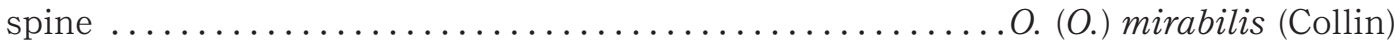

- Hind tibial spur smaller, less than 1/3 as long as hind tibia (Figs. 14, 22 and 29); costa (Figs. 2-3 and 5-6) ending at the end of $\mathrm{R}_{4+5}$; male sternites 5 not divided; female

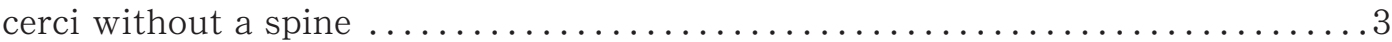

3. Male: Sternite 5 (Fig. 15) with a pair of distinct ventral appendages; epandrium (Fig. 16) with rather long setae; cercus (Fig. 16) with a tuft of long setae; paramere (Fig. 17) broad and perpendicularly curved apically ............. (O.) dolichodasys sp. nov.

- Male: Sternites 5 without ventral appendages; epandrium with sparse short setae; cerci without a tuft of long setae; paramere only slightly curved, never perpendicu-

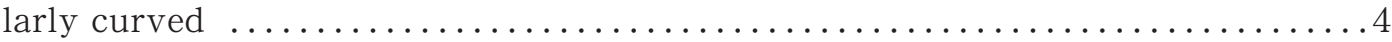

4. Male: Sternite 5 (Fig. 23) with a pair of distinct posterior lobes and a deep incision between them; cercus (Fig. 24) not prolonged ............ (O.) monticola sp. nov.

- Male: Sternite 5 without posterior lobes; cercus rather prolonged ............5

5. Wing (Fig. 6) somewhat yellowish. Male: Sternite 5 (Fig. 30) not concave posteromedially; surstylus (Fig. 31) with 2 strong setae on posteroventral corner; paramere (Fig. 32) strongly swollen apically ..................... spathulata sp. nov.

- Wing (Fig. 2) almost hyaline. Male: Sternite 5 (Fig. 9) distinctly concave posteromedially; surstylus (Fig. 10) without strong setae on posteroventral corner; paramere mostly parallel-sided, apically pointed (see Hayashi, 2009; Fig. 6)........... .

\section{Opalimosina (Hackmanina) czernyi (Duda, 1918) (Japanese name: Tserunî-chibifunkobae)}

(Figs. 1, 7-8)

Limosina (Scotophilella) czernyi Duda, 1918: 123.

Diagnosis. Body length 1.0-1.5 mm, body color mostly dark brown; eye rather large; $2 d c$, anterior small; 8 rows of $a c$ microsetae in front of suture; wing (Fig. 1) somewhat brownish, veins light brown; second costal sector almost as long as the third; hind tibia without a ventral spur; male abdominal sternite 5 as in Fig. 7; epandrium (Fig. 8) with rather long setae, cercus not prolonged; surstylus as in Fig. 8; paramere pointed; female cercus with 2 short spines.

Specimens examined. 1 오 Mt. Moiwa, Sapporo, Ishikari, Hokkaido, 11 June 1986, T. Hayashi; $1 \sigma^{\nearrow}$, Nanae, Oshima, Hokkaido, 20 Aug. 1982, T. Hayashi; 5 万 2 , 우, Mt. Myoko, Niigata, 29 June-2 July 1984, T. Hayashi; 1 우, Minakami, 900 m, Gunma, 23 May 2000, T. Hayashi; $1 \sigma^{\nearrow}$, Mt. Kumakura, Chichibu Mts., Saitama, 20 April 1989, T. Hayashi; 8 ऽ , 5 우, Moroyama, Iruma-gun, Saitama, 7-13 Aug. 1986, T. Hayashi; 1 우, ditto, 23 Mar. 1988, T. Hayashi; 1 ㅇ, ditto, 1 July 1991, T. Hayashi; 2 ऽ 1 우, Mt. Hiwada, Hidaka, Saitama, 25 April 1995, T. Hayashi; 2 ऽ, Mt. Kumotori, 1,150 m, Okutama, Tokyo, 28 April 1992, T. Hayashi; 1 우, ditto, 12 Sept. 1995, T. Hayashi; 3 조 1 우, Hikishoharadera, 46 m, Sakai-city, Osaka, 11-25 July 1983, K. Harusawa; 1 ㅇ․ Hagi City, Yamaguchi, 30-31 Aug. 2005, T. 


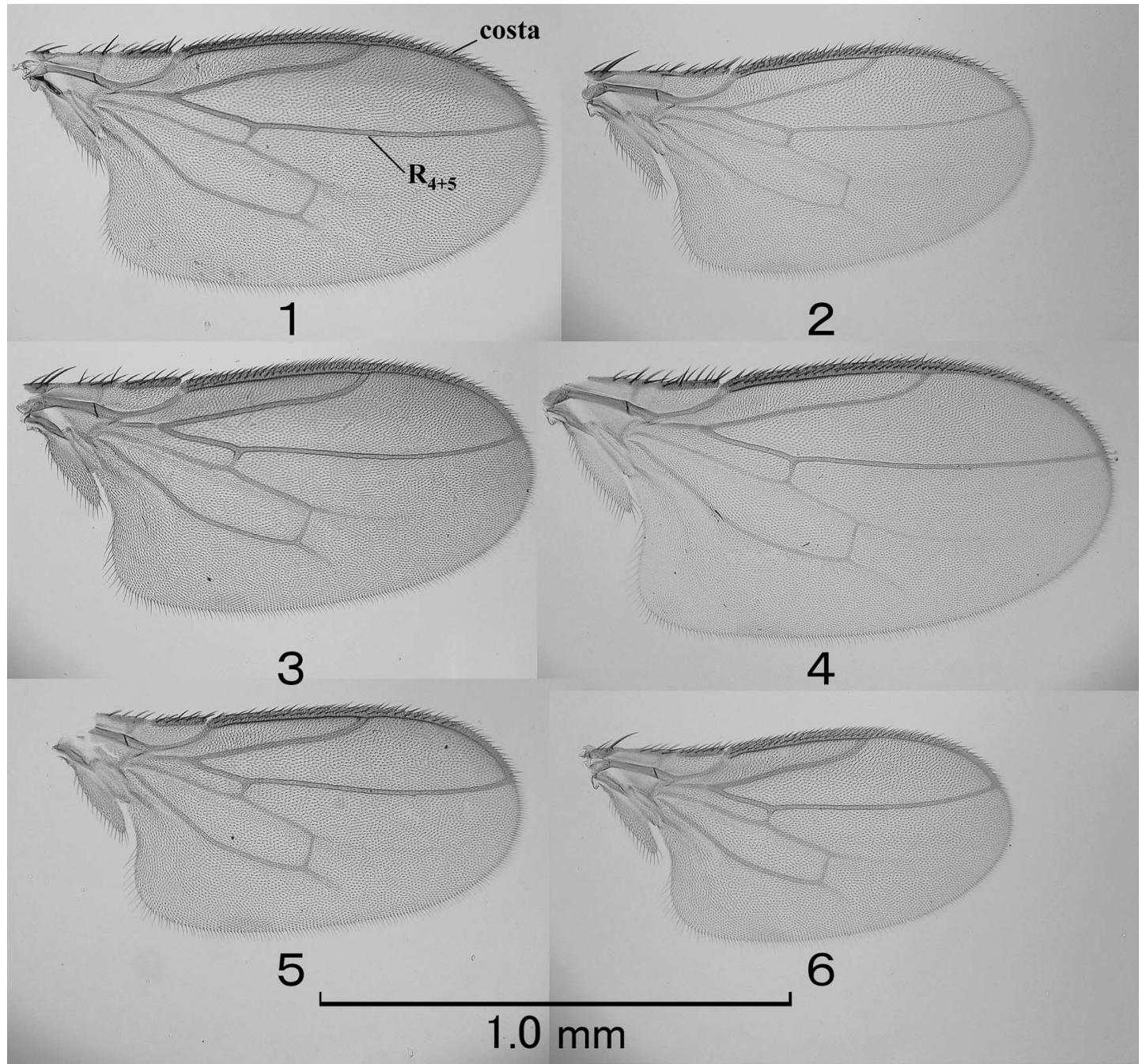

Figs. 1-6 Wings. 1, Opalimosina (Hackmanina) czernyi (male); 2, O. (O.) australis (male); 3, O. (O.) dolichodasys sp. nov. (paratype male); 4, O. (O.) mirabilis (male); 5, O. (O.) monticola sp. nov. (holotype male); 6, O. (O.) spathulata sp. nov. (paratype male).

Hayashi; $1 \sigma^{\text {T}}$, Chojagamori, Akiyoshidai, Yamaguchi, 28 Sept. 2005, T. Hayashi; 1 우, Mt. Gokahara-dake, 1,050 m, Nagasaki, 25 Mar.-23 April 1992, H. Kurahashi.

Distribution. Europe and Japan (Hokkaido, Honshu and Kyushu) (new record).

Opalimosina (O.) australis Hayashi, 2009 (Japanese name: Minami-kagizume-funkobae)

(Figs. 2, 9-10)

Opalimosina (Opalimosina) australis Hayashi, 2009: 221.

Diagnosis. Body length 0.9-1.3 mm, general color brown to dark brown; eye rather small; wing (Fig. 2) almost hyaline, veins pale yellow, costa ending at the end of $\mathrm{R}_{4+5}$, second costal sector almost as long as the third; hind tibia with a distinct ventral spine, 

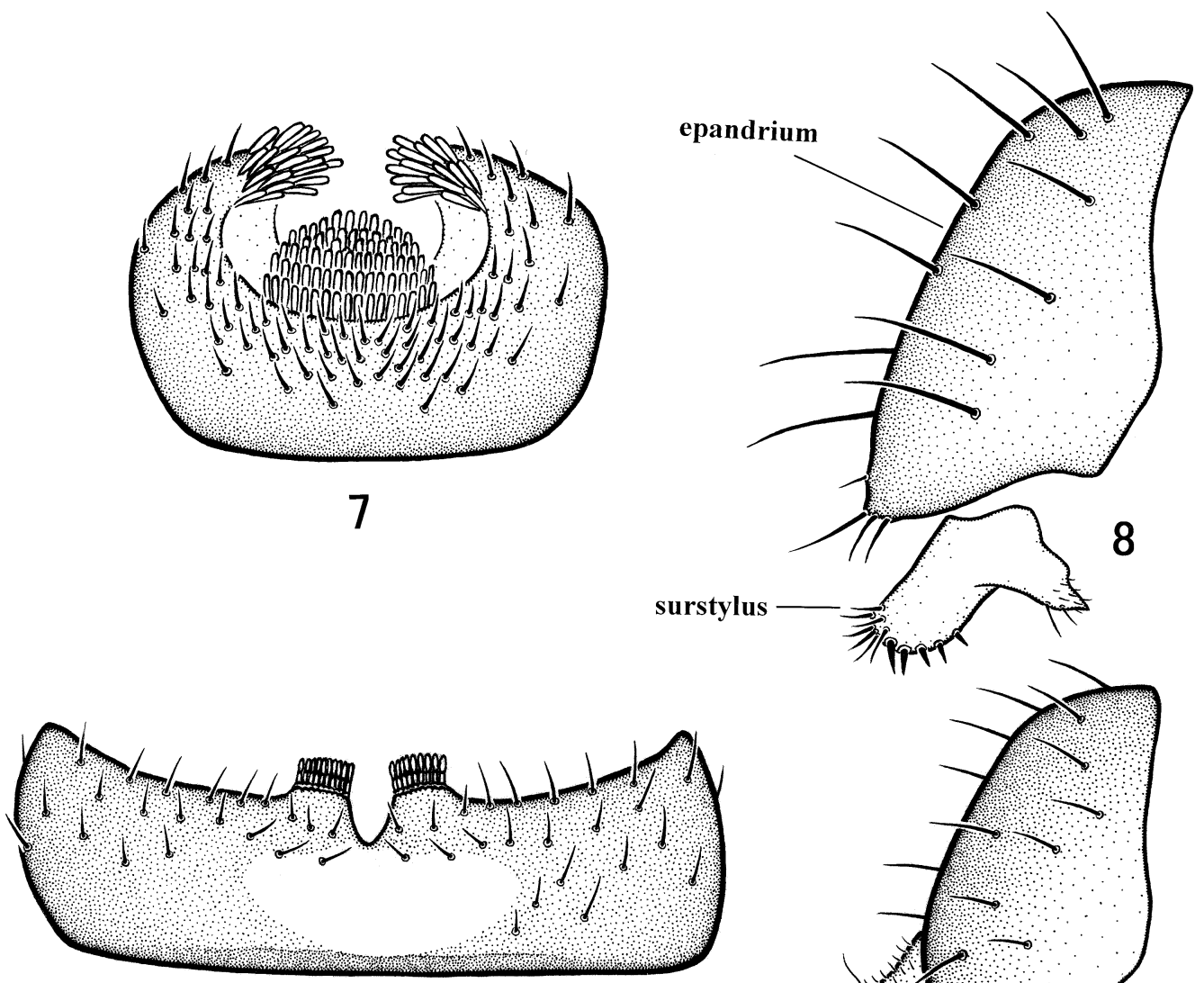

9
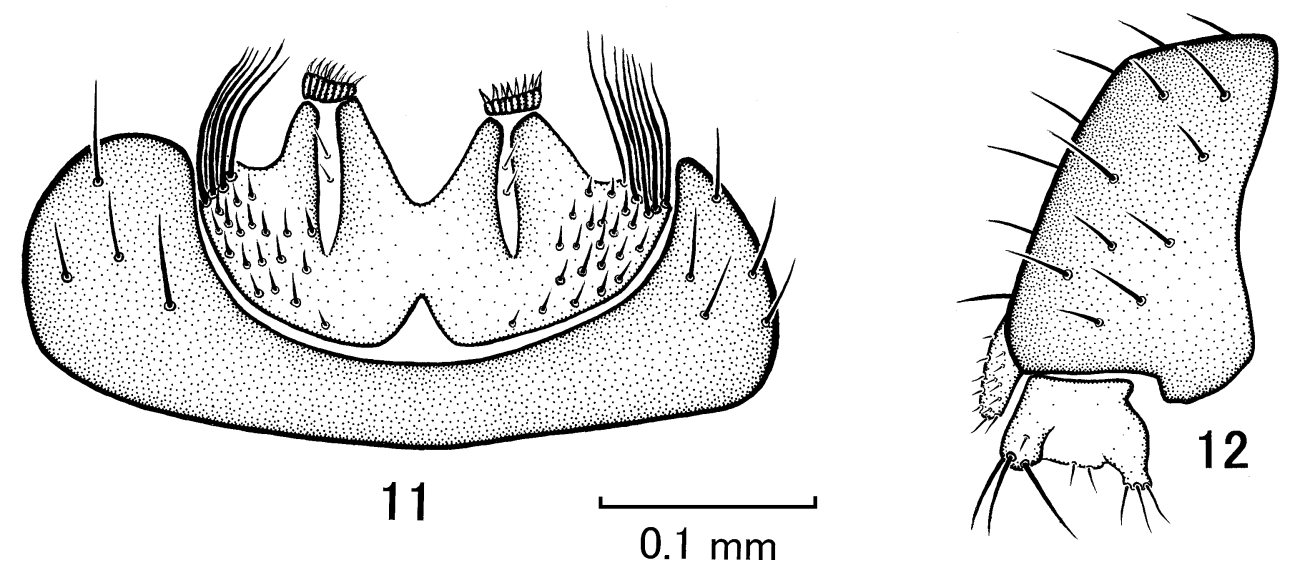

Figs. 7-13. 7, Opalimosina (Hackmanina) czernyi, male sternite 5; 8, O. (H.) czernyi, male terminalia, lateral view; 9, O. (O.) australis, male sternite 5; 10, O. (O.) australis, male terminalia, lateral view; $11, O$. (O.) mirabilis, male sternite $5 ; 12$, O. (O.) mirabilis, male terminalia, lateral view. 
about 1/5 as long as hind tibia; male abdominal sternite as in Fig. 9; epandrium (Fig. 10) with short and sparse setae, with a rather long cercus; surstylus as in Fig. 10, closely resembling those of O. calcalifera (Roháček, 1975) and O. spathulata Hayashi, sp. nov., but its posteroventral corner without strong setae; paramere mostly parallel-sided, apically pointed, epiphallus long and prolonged sharply (see Hayashi, 2009; Fig. 6); female cercus without strong spine.

Specimens examined. 2 ऽ, Yona, Okinawa-honto Is., Okinawa, 29 June-2 July, 1993, T. Hayashi.

Distribution. Pakistan, Indonesia, Papua New Guinea, Fiji and Japan (Okinawa-honto Is.) (new record).

\section{Opalimosina (O.) dolichodasys Hayashi, sp. nov. (Japanese name: Fusage-kagizume-funkobae)}

(Figs. 3, 13-19)

Body length 1.1-1.3 mm (holotype $1.2 \mathrm{~mm}$ ), general color brown to dark brown.

Head: Generally dark brown, anterior part of frons and gena somewhat brownish; 4 if, foremost one a little shorter; eye oval, its longest diameter about 3 times as long as narrowest genal width; antenna dark brown; arista about 5 times as long as first flagellomere, moderately long pubescent.

Thorax: Dark brown, brown microtomentose; $2 d c$, anterior one only slightly longer than microsetae; about 6 rows of irregular $a c$ microsetae in front of suture; upper part of katepisternum somewhat yellowish along suture, 2 kepst, anterior minute; scutellum rounded triangular, 2 sctl, apical sctl about 1.5 times as long as lateral sctl.

Wing (Fig. 3): Somewhat brownish, veins light brown; costa brown, ending at the end of $\mathrm{R}_{4+5}$; second costal sector a little longer than the third; $\mathrm{R}_{4+5}$ gently curved forwards; $\mathrm{r}-\mathrm{m}-\mathrm{dm}-\mathrm{cu}: \mathrm{dm}-\mathrm{cu}=$ about 2.5; halter with dark brown knob and brown stem.

Legs: Mostly brown to dark brown; mid tibial chaetotaxy as in Fig. 13, ventrally with av seta on basal 1/2 and strong apical seta; hind tibial spur (Fig. 14) small.

Abdomen: Dark brown, brown microtomentose. Male. Sternite 5 (Fig. 15) with deep incision posteromedially and with a pair of distinct ventral appendages each side of this incision, and with a row of setae outside each of this appendage; epandrium (Fig. 16) with rather strong setae, cercus with a batch of long setae; anterior part of surstylus (Fig. 16) prolonged, with rather strong setae, posterior part with fine sinuate hairs; apical part of epiphallus (Fig. 17) slender and sinuate, with pointed apex, paramere (Fig. 17) rather wide, perpendicularly curved. Female. Postabdomen as in Figs. 18 and 19; tergite 9 completely fused with cerci; cercus without a conspicuous spine; spermathecae were not observed because of its deflation.

Type series. Holotype: $\sigma^{7}$, Lake Shikotsu, Chitose, Ishikari, Hokkaido, JAPAN, 31 Aug. 1995, T. Hayashi. Paratypes. 2 ㄱ, 3 우, same data as holotype.

Etymology. The specific name refers to a batch of long setae on male cercus (Greek: dolichos + dasys).

Distribution. Japan (Hokkaido).

Remarks. This species is easily distinguished from the other members by male postabdominal structures. Having long setae on male cercus is a very unique character among the members of this genus (some undescribed Oriental species share this character).

All individuals were collected on human dung in forest. 

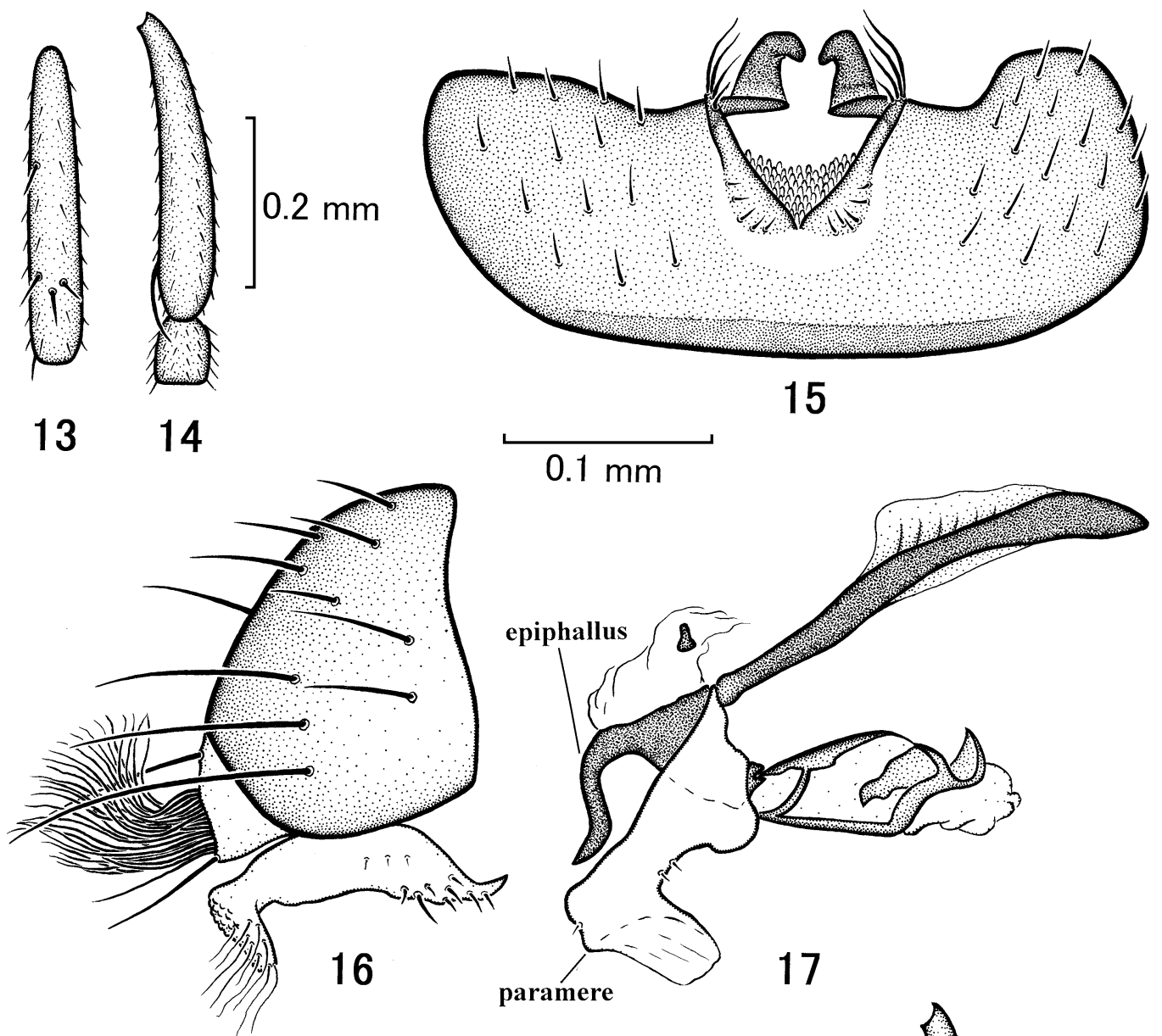

\section{5}

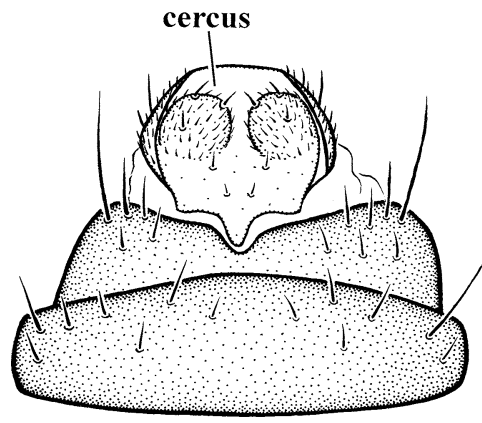

18

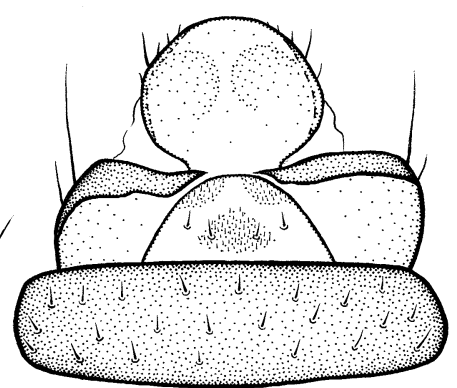

19

\section{$0.2 \mathrm{~mm}$}

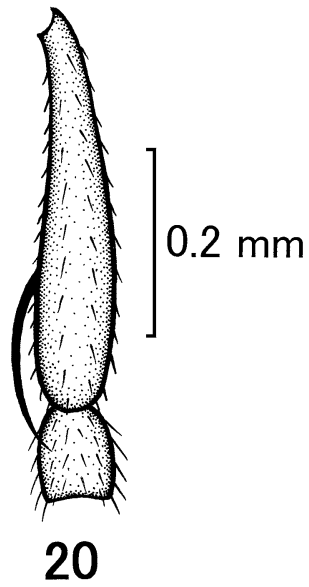

Figs. 13-20. 13, Opalimosina (O.) dolichodasys sp. nov., right mid tibia, dorsal view; 14, right hind tibia, anterior view; 15, male sternite 5; 16, male terminalia, lateral view; 17, male inner genitalia; 18, female terminalia, dorsal view; 19, ditto, ventral view; 20, O. (O.) mirabilis, right hind tibia, anterior view. 


\section{Opalimosina (O.) mirabilis (Collin, 1902) \\ (Japanese name: Ô-kagizume-funkobae)}

(Figs. 4, 11-12, 20)

\section{Limosina mirabilis Collin, 1902: 59.}

Diagnosis. Body length 1.1-1.5 mm, general color brown to dark brown; eye rather small; wing (Fig. 4) almost hyaline, veins pale yellow, costa a little beyond the end of $\mathrm{R}_{4+5}$, second costal sector as long as or a little longer than the third; hind tibia (Fig. 20) with a large ventral spine, nearly $1 / 2$ as long as hind tibia; male abdominal sternite 5 (Fig. 11) divided into 2 parts by membraneous stripe, posteromedial part with a batch of long setae; epandrium (Fig. 12) with short and sparse setae, with a rather long cercus; surstylus as in Fig. 12; paramere gradually tapered toward apex, epiphallus sharply prolonged; female cercus with an apically curved distinct spine.

Specimens examined (except for records by Hayashi (1986, 2005)). 1 우, Iwaobetsu, Shiretoko Pen., Abashiri, Hokkaido, 19-20 Aug. 1995, T. Hayashi; 13 지 11 우, Nemuro, Nemuro, Hokkaido, 22 Aug. 1995, T. Hayashi; 3 o $^{\top}, 2$ 우, Sapporo, Ishikari, Hokkaido, 3 Sept. 2002, T. Hayashi; 2 ㅇ, Jozankei, Sapporo, Ishikari, Hokkaido, 5 Sept. 1995, T. Hayashi; 1 우, Lake Shikotsu, Chitose, Ishikari, Hokkaido, 31 Aug. 1995, T. Hayashi; 2 ऽ’, Moroyama, Iruma-gun, Saitama, 11 Aug. 1986, T. Hayashi; 1 ऽ , Mt. Kumotori, 1,150 m, Okutama, Tokyo, 30 July 1986, T. Hayashi; 2 ð , Taishakukyo, Tojo-cho, Hiroshima, 6 June 1997, T. Hayashi; 1 ऽ, Yona, Okinawa-honto Is., Okinawa, 2-6 Mar. 1994, T. Hayashi.

Distribution. Europe, Russia, Mongolia, North Korea, North America, Central and South America, Pakistan, Australia, New Zealand, Hawaii and Japan (Hokkaido, Honshu, Kyushu and Okinawa-honto Is.)

\section{Opalimosina (O.) monticola Hayashi, sp. nov. (Japanese name: Miyama-kagizume-funkobae)} (Figs. 5, 21-27)

Body length 1.0-1.3 mm (holotype $1.0 \mathrm{~mm}$ ), general color brown to dark brown.

Head: Generally dark brown, anterior part of frons somewhat brownish; 4 if, foremost one a little shorter; eye oval, its longest diameter about 3 times as long as narrowest genal width; antenna dark brown; arista about 5 times as long as first flagellomere, moderately long pubescent.

Thorax: Dark brown, brown microtomentose; $2 d c$, anterior one only slightly longer than microsetae; about 6 rows of irregular $a c$ microsetae in front of suture; upper part of katepisternum somewhat yellowish along suture, 2 kepst, anterior minute; scutellum rounded triangular, 2 sctl, apical sctl about 1.5 times as long as lateral sctl.

Wing (Fig. 5): Somewhat brownish, veins light brown; costa brown, ending at the end of $\mathrm{R}_{4+5}$; second costal sector as long as or a little longer than the third; $\mathrm{R}_{4+5}$ gently curved forwards; $\mathrm{r}-\mathrm{m}-\mathrm{dm}-\mathrm{cu}: \mathrm{dm}-\mathrm{cu}=$ about 2.5; halter with dark brown knob and brown stem.

Legs: Mostly brown to dark brown; mid tibial chaetotaxy as in Fig. 21, ventrally with av seta on basal $1 / 2$ and strong apical seta; hind tibial spur (Fig. 22) small.

Abdomen: Dark brown, brown microtomentose. Male. Sternite 5 (Fig. 23) deeply incised posteromedially and with a pair of posterior lobes each side of this incision, which have a row of teeth-like structures posteriorly; epandrium (Fig. 24) with sparse short setae, cercus not prolonged; surstylus (Fig. 24) somewhat prolonged anteriorly; epiphallus (Fig. 25) rather straight; paramere (Fig. 25) gently sinuate, somewhat boot-shaped. 

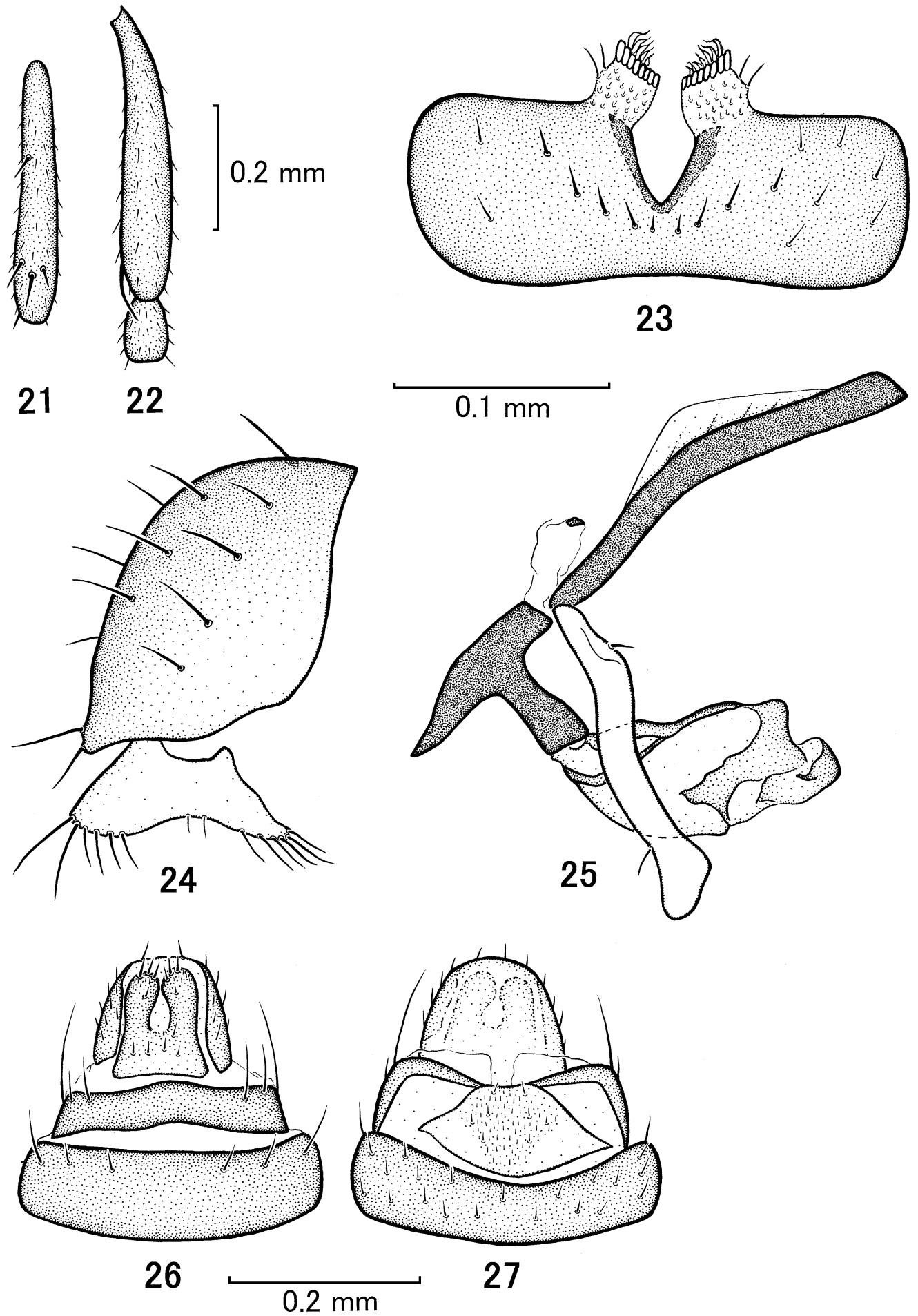

Figs 21-27. Opalimosina (O.) monticola sp. nov., 21, right mid tibia, dorsal view; 22, right hind tibia, anterior view; 23, male sternite 5; 24, male terminalia, lateral view; 25, male inner genitalia; 26, female terminalia, dorsal view; 27 , ditto, ventral view. 
Female. Postabdomen as in Figs. 26 and 27; tergite 9 completely fused with cerci; cercus without a strong spine; spermathecae almost as in those of O. australis (see Hayashi, 2009; Fig. 9).

Type series. Holotype: ऽד, Mt. Norikuradake, Azumi Villege, Nagano, 25-26 June 1988, T. Hayashi. Paratypes. 1 万', Kamikawa, Kamikawa, Hokkaido, 16 Aug. 1982, T. Hayashi; 1 우, same data as holotype.

Etymology. The specific name means “dweller on mountain” in English, derived from the high altitude collection site of holotype.

Distribution. Japan (Hokkaido and Honshu).

Remarks. This species is easily distinguished from the other members of the genus Opalimosina by male postabdominal structures.

The specimen from Hokkaido was obtained on cow dung.

\section{Opalimosina (O.) spathulata Hayashi, sp. nov. (Japanese name: Heragata-kagizume-funkobae)}

(Figs. 6, 28-34)

Body length $0.8-1.2 \mathrm{~mm}$ (holotype $1.1 \mathrm{~mm}$ ), general color brown to dark brown.

Head: Generally dark brown, anterior part of frons somewhat brownish; 4-5 if, foremost one a little shorter; eye oval, its longest diameter about 2.5 times as long as narrowest genal width; antenna dark brown; arista about 5 times as long as first flagellomere, moderately long pubescent.

Thorax: Dark brown, brown microtomentose; $2 d c$, anterior one only slightly longer than microsetae; about 6 rows of irregular $a c$ microsetae in front of suture; upper part of katepisternum somewhat yellowish along suture, 2 kepst, anterior minute; scutellum rounded triangular, 2 sctl, apical sctl about 1.5 times as long as lateral sctl.

Wing (Fig. 6): Somewhat yellowish, veins yellowish brown; costa light brown, ending at the end of $\mathrm{R}_{4+5}$; second costal sector as long as the third; $\mathrm{R}_{4+5}$ gently curved forwards; $\mathrm{r}-\mathrm{m}-\mathrm{dm}-\mathrm{cu}: \mathrm{dm}-\mathrm{cu}=$ about 2.2; halter with dark brown knob and brown stem.

Legs: Mostly brown to dark brown; mid tibial chaetotaxy as in Fig. 28, ventrally with $a v$ seta on basal $1 / 2$ and strong apical seta; hind tibial spur (Fig. 29) rather small, about $1 / 3$ as long as hind tibia.

Abdomen: Dark brown, brown microtomentose. Male. Sternite 5 (Fig. 30) not strongly incised posteromedially and with a pair of characteric structures posteriorly; epandrium (Fig. 31) with short and sparse setae; surstylus (Fig. 31) resembling those of O. australis and $O$. calcalifera, its posteroventral corner with 2 strong setae; epiphallus (Fig. 32) large and blunt; paramere (Fig. 32) with strongly swollen apex. Female. Postabdomen as in Figs. 33 and 34; tergite 8 simple, without thumb-like lateral projections; tergite 9 completely fused with cerci; cercus without strong spine; spermathecae almost as in those of O. australis (see Hayashi, 2009; Fig. 9).

Type series. Holotype: ð๐, Banna, Ishigaki Is., Okinawa, 7-9 Mar. 1994, T. Hayashi. Paratypes. 1 ㅇ, Onneyu, Kitami, Abashiri, Hokkaido, 13 Aug. 1982, T. Hayashi; $1 \sigma^{7}$, Nissho Pass, 1,023 m, Hokkaido, 9-10 Aug. 1994, T. Hayashi; 7 б , 1 우, Lake Shikotsu, Chitose, Ishikari, Hokkaido, 31 Aug. 1995, T. Hayashi; 1 ऽ , Mt. Yokotsudake, Nanae, Oshima, Hokkaido, 20 Aug. 1982, T. Hayashi; 9 그, 2 우, Nanae, Oshima, Hokkaido, 19-21 June 1982, T. Hayashi; $1 \sigma^{7}, 2$ 우, ditto, 20-22 Aug. 1982, T. Hayashi; 1 우, Mt. Myoko, Niigata, 29 June - 2 July 1984, T. Hayashi; 2 ㅇ, Yabuzuka, Nitta-gun, Gunma, 9 July 1995, T. Hayashi; 10 o $^{\top}, 24$ ㅇ, Moroyama, Iruma-gun, Saitama, 29 July - 20 Aug. 1986, T. Hayashi; $5 \sigma^{\text {T}}$, ditto, 17 Sept. 1987, T. Hayashi; $1 \sigma^{\nearrow}$, ditto, 28 May 1988, T. Hayashi; $1 \sigma^{\top}$, ditto, 18 Sept. 1989, T. Hayashi; 1 ऽ, ditto, 14 July 1990, T. Hayashi; 1 ㅇ․ Mt. Kumotori, 

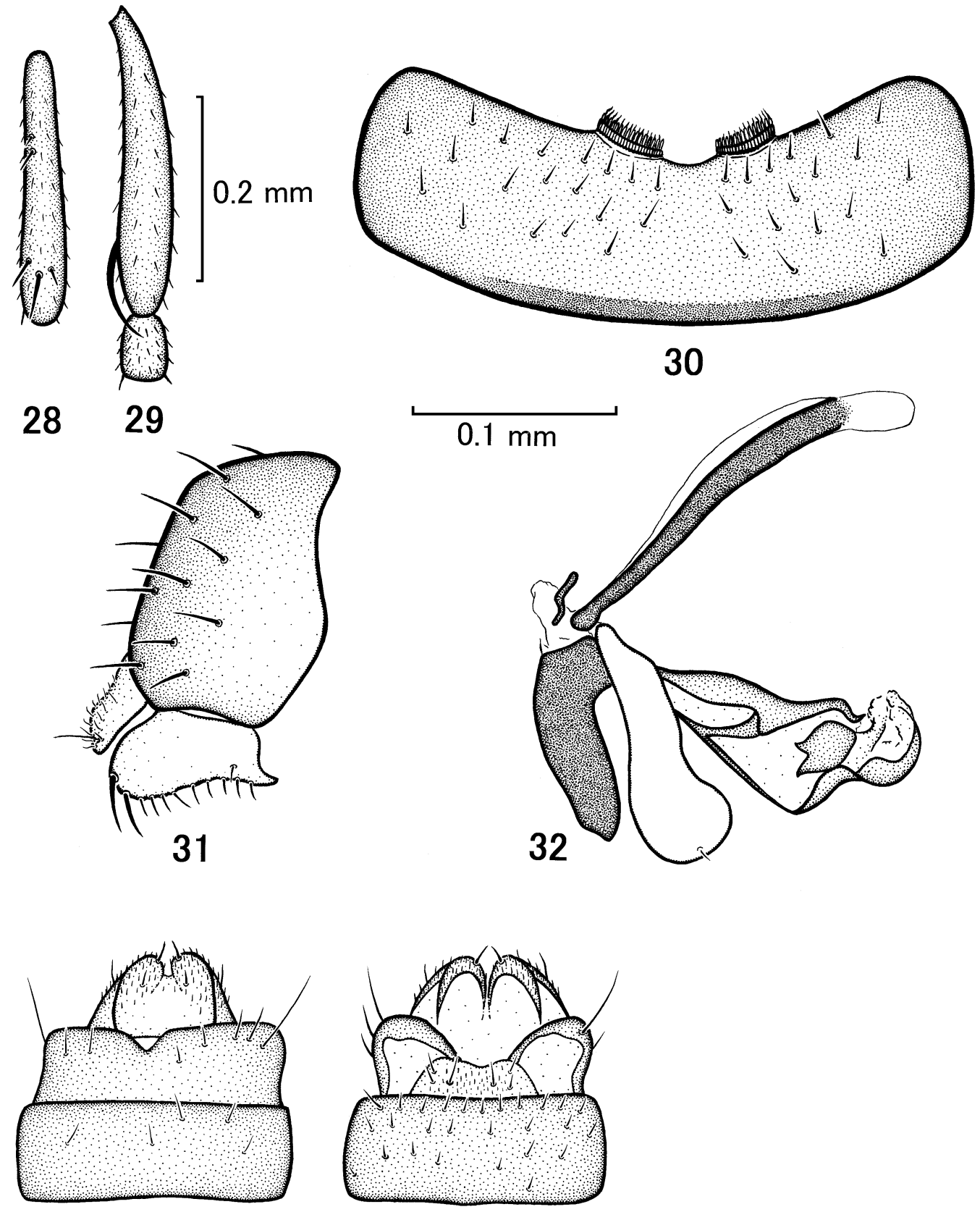

33

\section{4}

Figs. 28-34. Opalimosina (O.) spathulata sp. nov., 28, right mid tibia, dorsal view; 29, right hind tibia, anterior view; 30, male sternite 5; 31, male terminalia, lateral view; 32 , male inner genitalia; 33, female terminalia, dorsal view; 34 , ditto, ventral view. 
Okutama, Tokyo, 27 July 1992, T. Hayashi; 1 우, Mt. Takao, Tokyo, 30 June 1983, T. Hayashi; 2 ㄱ, 4 우, ditto, 4 Oct. 1983, T. Hayashi; 2 우, ditto, 27 Sept. 1984, T. Hayashi; 1 우, Minamitama, Tokyo, 5 Sept. 1982, T. Hayashi; 1 б hima, 6 June 1997, T. Hayashi; 1 ㅇ, Ikumonaka, Ato-cho, Abu-gun, Yamaguchi, 26 July 2005, T. Hayashi; $1 \sigma^{\nearrow}$, Hagi, Yamaguchi, 30-31 Aug. 2005, T. Hayashi; $1 \sigma^{\nearrow}$, Yona, Okinawa-honto Is., Okinawa, 1-2 July, 1993, T. Hayashi; $2 \sigma^{\top}, 2$ 우, same data as holotype; 2 ऽ, 4 우, Komi, Iriomote Is., Okinawa, 10-12 Mar. 1994, T. Hayashi.

Etymology. The specific name refers to spatula-shaped paramere.

Distribution. Japan (Hokkaido, Honshu, Okinawa-honto Is., Ishigaki Is. and Iriomote Is.)

Remarks. This species is closely related to $O$. calcarifera and $O$. australis in general appearance and structures of male genitalia. The most discriminating feature from these species is the shape of paramere, i.e., its apex of this species is much swollen (Fig. 32).

\section{REFERENCES}

Hayashi, T. 1986a. Studies on the sphaerocerid flies of synanthropy and hygienic importance in Japan (Diptera).

I. The key to species of the flies. Jpn. J. Sanit. Zool., 37: 113-120.

Hayashi, T. 1986b. Studies on the sphaerocerid flies of synanthropy and hygienic importance in Japan (Diptera). II. Records of the forty species. Jpn. J. Sanit. Zool., 37: 193-204.

Hayashi, T. 1989. The genus Opalimosina (s. str.) Roháček, 1983 from Pakistan (Diptera, Sphaeroceridae). Jpn. J. Sanit. Zool., 40 (suppl.): 61-64.

Hayashi, T. 2005. New distributional records and taxonomic notes on the Japanese lesser dung flies (Diptera, Sphaeroceridae). The dipterist's Club of Japan 'HANA ABU', 19: 5-12 (in Japanese).

Hayashi, T. 2009. A new species of the genus Opalimosina Roháček (Diptera, Sphaeroceridae) from the Oriental and Australasian Regions. Med. Entomol. Zool., 60: 221-224.

Papp, L. 1991. Oriental Limosininae: new species and records (Diptera, Sphaeroceridae). Acta Zoologica Hungarica, 37: 225-251.

Roháček, J. 1983. A monograph and reclassification of the previous genus Limosina Macquart (Diptera, Sphaeroceridae) of Europe. Part II. Beitr. Entomol., 33: 3-195. 